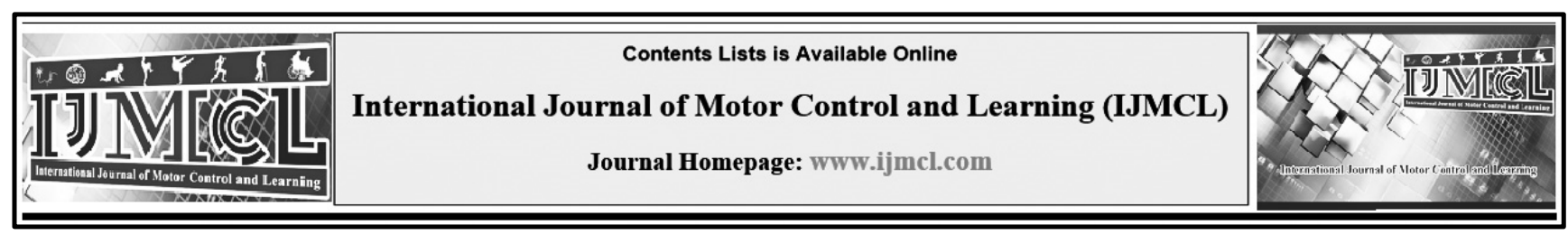

\title{
The Effect of Skill Level on Darts Throwers' Use of Different Mental Skills
}

\author{
Mohammad Reza Shahabi Kaseb ${ }^{a^{*}}$, Linda J. Duffy ${ }^{\mathrm{b}}$, Arezou Mehranian ${ }^{\mathrm{c}}$, Ali Reza Aminaee ${ }^{\mathrm{d}}$
}

\footnotetext{
a Assistant Professor in Motor Behavior, Hakim Sabzevari University, Faculty of Sport Science, Sabzevar, Iran

${ }^{\mathrm{b}}$ Associate Professor in Psychology, Middlesex University, School of Science and Technology, London, UK

${ }^{\mathrm{c}} \mathrm{Ph}$.D. Student in Motor Control, Shahid Beheshti University, Tehran, Iran

${ }^{\mathrm{d}} \mathrm{Ph} . \mathrm{D}$. Student in Motor Control, Tehran University, Tehran, Iran
}

\begin{tabular}{l}
\hline Keywords \\
\hline Psychological Skills \\
Darts Throwers \\
Elite \\
Beginner
\end{tabular}

Mohammad Reza Shahabi Kaseb. Email: mr.shahabi@hsu.ac.ir

Received: 2020/05/08 Accepted: 2020/08/18 Published: 2020/08/21

\begin{abstract}
Background: In recent years sports psychologists, coaches and athletes have paid a greater focus of attention to mental wellbeing and psychological skills. The purpose of this study was to investigate which psychological skills are important to two levels of skills among Darts players, namely; elite and beginner.

Method: The sample consisted of 24 elite and 24 beginner Darts throwers. In order to gain insight into Darts throwing, beginner Darts players attended a national-championshipsimulated competition. Both elite and beginner players also completed the Ottawa Mental Skill Questionnaire.

Results: Independent t-test results showed that there was a significant difference just in basic psychiatric skills between the beginner and elite Darts throwers $(p<0.05)$. Nevertheless, there is no statistically significant difference in Ottawa's mental skills, psychosomatic skills and cognitive skills between beginner and elite Darts throwers $(p>0.05)$.

Conclusion: Results revealed differences between elite and beginner Darts players in foundation mental skills and commitment and mental practice subscales. Furthermore, results showed that for the commitment skill, elite and beginner Darts throwers were at the highest and lowest level respectively.
\end{abstract}

\section{Introduction}

Optimal performance of sport skills depends on physical fitness, psychological skills and arguably certain unknown factors. Psychological skills can be attributed to the athlete's inherent or acquired characteristics, which are the main and proven performance components in high level sports competitions (Pashabadi et al., 2011). Researchers divided psychological skills into three subsets; Foundation skills, Psychosomatic skills and Cognitive skills. Foundation skills include goalsetting, self-confidence and commitment, they are named "basic" because other mental skills will not be developed further unless these are stabilized in the athlete. Psychosomatic skills, which are associated with the physiological characteristics of athletes, are divided into four skills, namely stressreaction, fear control, psychological relaxation and activation. Finally, cognitive skills are associated with cognitive processes such as learning, perception, memory, thinking, mental imagery, mental practice, focusing, and planning, specifically in relation to preparation for competition (Durand-Bush, Salmela, \& Green- 
Demers, 2001). Changes in each of these mental skills in athletes not only affect their performance, but also may determine differences between elite athletes and other athletes (Weinberg \& Gould, 2007).

Despite the importance of psychological skills, only a limited number of athletes are aware of the most effective ways of acquiring, using and developing such skills (Esfahani \& GHezelseflo, 2013). Many athletes, whilst having the required physical fitness and technical attributes may fail in competition due to poor mental preparation; thus, determining the strengths and weaknesses of the psychological skills' set of athletes, particularly assessing the level and frequency of their use is an important part of preparation. Moreover an evaluation of athletes' progress in the use of psychological skills and distinguishing successful athletes from unsuccessful ones accordingly, is of vital importance (Taylor \& Wilson, 2005). Therefore, the role of sport psychologists, besides conducting extensive research to identify psychological skills that have an impact on the successful implementation of various sports, need to be able to identify the effective strategies and techniques used by elite athletes (Orlick \& Partington, 1988).

In this regard, researchers stated that elite athletes use the psychological skills of imagery, goal-setting, arousal control and planning in order to reach their highest level of performance (Krane, Williams, \& Williams, 2014). Pashabadi et al. (2011) used the Ottawa Mental Skills Questionnaire to compare the mental skills of elite and non-elite women and men volleyball players. By surveying 104 volleyball players, they found that elite players are at a higher level than non-elite players in skills of concentration, confidence and mental efficiency (Pashabadi et al., 2011). Sotoodeh, Talebi, Hemayattalab, and Arabameri (2012) also used the Ottawa questionnaire to compare various mental skills among 88 men and 54 women elite and non-elite Taekwondo athletes. The results showed that elite performers were more skilled in the competition planning, goal-setting, activation, relaxation, confidence, and commitment than their non-elite counterparts. However, non-elite performers achieved higher scores than elite performers on stress-reaction and refocusing skills (Sotoodeh, Talebi, Hemayattalab, \& Arabameri, 2012). Furthermore, vazini Taher and Shahbazi (2013) found that the greatest difference in mental skills between elite and nonelite football players of 12 to 16 years of age were seen in concentration, activation and refocusing (Vazini Taher \& Shahbazi, 2013).

It appears, therefore, from much of the previous research, that due to the vast differences between rules, strategies, and the manner in which each sport is performed, that optimal performance across all sports discipline's hinges on a variety of sports specific psychological factors. For example, in the sport of Wrestling psychological control and imagery skills are pivotal (Mirzaee, Rahmani-nia, \& Bordar, 2007), in Hockey, commitment, selfconfidence and goal-setting are the most important factors (Eloff, Monyeki, \& Grobbelaar, 2011), wheras mental skills training particularly triaining 
of goal-setting, positive self-talk and imagination which had positive effects on self-confident are among those factors which are important for volleyball player (Heydari, Soltani, \& Mohammadi-Nezhad, 2018).

Arguably Darts is a sport where elite competitors display a high level of mental competence; e.g., Darts throwing skill requires positive control of thoughts, feelings and behaviors that are directly related to certain parts of the nervous system that are involved in controlling aspects of skill implementation (Low \& Nelson, 1994). Research on the psychology of Darts throwers suggests that psychological skills, such as self-talk and mental imagery (Afsanepurak, Bahram, \& Dana Amir, 2012; Cumming, Nordin, Horton, \& Reynolds, 2006), educational self-talk (Aghdasi, Torabi, \& Touba, 2013), Mental thoughness (Zhang et al., 2016) and motor imagery (Dahm \& Rieger, 2019; Weber \& Doppelmayr, 2016) all have an effect on Darts throwing performance. For example, in a study, researchers examined the effect of subjective imagery and selftalk on the performance of Darts throwers in 75 adolescents. The results showed that teenage Darts throwers may use a combination of different mental skills to achieve success (Afsanepurak et al., 2012). In previous research Stroub (1989) compared three different psychological training programs amongst Darts throwers. The first program included the utilization of mental skills related to relaxation techniques, goal-setting, imagery and self-esteem. The second program included relaxation, concentration, problem solving and subjective review and the third program involved attention control, emotional control, activation, physical awareness, cognitive restructuring, mind planning and improving and maintaining confidence. The results of this study showed that the practice of psychological skills significantly improved performance of Darts throwers; the results also indicated an interaction between the level of skill of the Darts throwers and the type of psychological technique employed by them (Straub, 1989). further, researchers show that mindfulness training in darts learning for beginners not only appeard to be adaptive for their sport experience and performance, it also seemed to reduce the deterioration of the acquired skill level after the end of sport training (Zhang et al., 2016). Given that psychological skills are considered as factors influencing the desired performance of sport skills and such skills are used in many different sports, the aim of this study was to investigate and compare psychological skills in elite and beginner Darts throwers.

\section{Method}

Participants: The research method was postevent (causal-comparative). In this study 24 available Darts throwers $\left(M_{\text {age }}=28.79 \pm 10.44\right.$ years) attending in the Darts National League in 2016 (elite ones) were conveniently participated in our study as elite group. Therefore, other 24 participants were randomly selected from students of Hakim Sabzevari University except physical education students $\left(M_{\text {age }}=22.50 \pm 2.43\right.$ years $)$ who 
had no history of Darts playing, among them 24 were selected randomly as a beginner group.

Data Gathering Tool: The Ottawa Psychological Assessment Questionnaire (OMSAT-3) consists of 48 questions and measure 12 psychological skills (goal-setting, selfconfidence, commitment, stress response, relaxation, fear control, activation, concentration, refocusing, visualization, mental practice, and competition design) in three categories of basic mental skills, psychosomatic skills, and cognitive skills. The validity of the Persian version of this questionnaire was reviewed through confirmatory factor analysis and the structure of 12 factors 48 questions was confirmed. The internal consistency of the entire questionnaire was .81 and for the subscales in the range of $.65 \ldots .76$, and its reliability for the whole questionnaire was .76 and for the sub-scales in the range of $.72 \ldots .84$ (Zeidabadi, Rezaie, \& Motashareie, 2014).

Implementation Method: After selecting the sample, elite Darts throwers completed the Ottawa Psychological Assessment Questionnaire. Beginner participants, after completing their informed consent form, were learned to throw Darts within two 45-minutes sessions of Darts instruction conducted by a specialized Darts coach. Then, each participant performs 21 throws and their errors were corrected by Darts coach. After completion of learning sessions, beginners attended the pre-test session. In pre test, all beginners performed 9 throws and the total scores were recorded for each of them. After that, they attended four sessions of practice. In each practice session that was held in 4 consecutive day, beginners perform 6 blocks of 9 Darts throwing trials. altogether, they threw 216 Darts in four practice sessions. In acquisition test, again, beginners threw 9 darts and their scores were also recorded. After three weeks without any practice, beginners attended the retention test which conducted similar to acquisition test. Data of pretest, acquisition and retention tests were analyzed in order to reveal that learning occurred. Since the OMSAT questionnaire is associated with competitive athletes, the participants of the beginner group were summonded for a Darts tournament which was indeed simulated tournament similar to the real national tournament condition and with real rewards for winners. Finally, when the tournament was finished, beginners completed the questionnaire.

Statistical tests: For statistical description of data, the central tendencies (mean), dispersion (standard deviation) and graphs were used. For statistical inference of the data, repeated measure ANOVA test was used to determine whether learning had occurred for beginners. Also, independent t-test was used and Friedman nonparametric test applied for evaluation of psychological skills at a significant level of $\alpha=.05$.

\section{Results}

In preliminary data analysis, A repeated measures ANOVA revealed that there are statistically significant deference in Darts scores of beginners recorded from pretest, acquisition and retention test $(\mathrm{F}(2,10)=12.284$, 
$\mathrm{P}=.002$; Wilk's $\lambda=0.289$, partial $\eta 2=.711$ ). Post hoc tests using the Bonferroni correction showed that mean scores of beginners were higher in acquisition test (120.75 \pm 29.696) and retention test $(124.5 \pm 27.695)$ than pre-test $(91.83 \pm 18.949)$, which was statistically significant for pre-test and acquisition comparison $(\mathrm{p}=.008)$, pre-test and retention comparison $(\mathrm{p}=.018)$ but no significant for acquisition and retention comparison $(\mathrm{p}=1.000)$.

The descriptive results of Ottawa's mental skills and its three components (foundation, psychosomatic, and cognitive skills) showed that, apart from the average psychosomatic skills in which beginner throwers scored higher, cognitive skills, foundation skills, and Ottawa's mental skills (total score) of elite Darts throwers have a higher score (see Table 1 for Mean and SD of Dart throwers' mental skills scores).

Table 1. The Mean and Standard Deviation of Ottawa's mental skills and its sub-scales.

\begin{tabular}{ccccc}
\hline Skill level & $\begin{array}{c}\text { Ottawa Mental } \\
\text { Skills }\end{array}$ & Foundation skills & $\begin{array}{c}\text { Psychosomatic } \\
\text { skills }\end{array}$ & Cognitive skills \\
\cline { 2 - 5 } & $\mathrm{M} \pm \mathrm{SD}$ & $\mathrm{M} \pm \mathrm{SD}$ & $\mathrm{M} \pm \mathrm{SD}$ & $\mathrm{M} \pm \mathrm{SD}$ \\
\hline Elite & $238.54 \pm 23.53$ & $69.33 \pm 8.46$ & $74.42 \pm 10.12$ & $94.79 \pm 9.82$ \\
Beginner & $231.46 \pm 21.68$ & $60.33 \pm 7.88$ & $78.04 \pm 10.74$ & $93.08 \pm 9.25$ \\
\hline
\end{tabular}

Independent t-test results showed that there was a significant difference just in basic psychiatric skills between the beginner and elite Darts throwers $(p<$ $.05)$. Nevertheless, there is no statistically significant difference in Ottawa's mental skills, psychosomatic skills and cognitive skills between beginner and elite Darts throwers $(p>.05)$. (see Table 2 for comparison of the elite and beginner groups).

Further investigation of the sub-scales of psychological skills in each component showed that there is a significant statistical difference between elite and beginner Darts throwers in the sub-scales of commitment $(t=58 / 4, \mathrm{p}=.0001)$ and Mental Practice $(t=51.2, p=.015)$. The results of Friedman test, for ranking the sub-scales of the psychological skills of Darts throwers, showed that in the elite throwers, sub-scales of self-confidence, commitment and goal-setting, were three subscales with the highest levels, and stress-response, concentration, and refocusing were three subscales with the lowest levels, respectively. However, in the beginner Darts throwers, the confidence, fear control, and goal-setting were three sub-scales with the highest levels and commitment, stress responses and mental practice were three sub-scales with the lowest levels (see Figure 1 for psychological skills' ranking between elite and beginner groups). 
Table 2. Results of Independent t-test for comparison of Ottawa's mental skills and its sub-scales.

\begin{tabular}{cccccc}
\hline & $\begin{array}{c}\text { Average } \\
\text { elite scores }\end{array}$ & $\begin{array}{c}\text { Average beginner } \\
\text { scores }\end{array}$ & t Value & $\begin{array}{c}\text { Degrees of } \\
\text { freedom }\end{array}$ & Significant \\
\hline $\begin{array}{c}\text { Ottawa mental } \\
\text { skills }\end{array}$ & 238.5 & 231.4 & 1.08 & 46 & .28 \\
$\begin{array}{c}\text { Foundation skills } \\
\text { psychosomatic } \\
\quad \text { skills }\end{array}$ & 69.33 & 60.33 & 3.81 & 46 & $.0001^{*}$ \\
Cognitive skills & 74.4 & 78.04 & 1.2 & 46 & .23 \\
\hline
\end{tabular}

$\mathrm{P}=0.05$

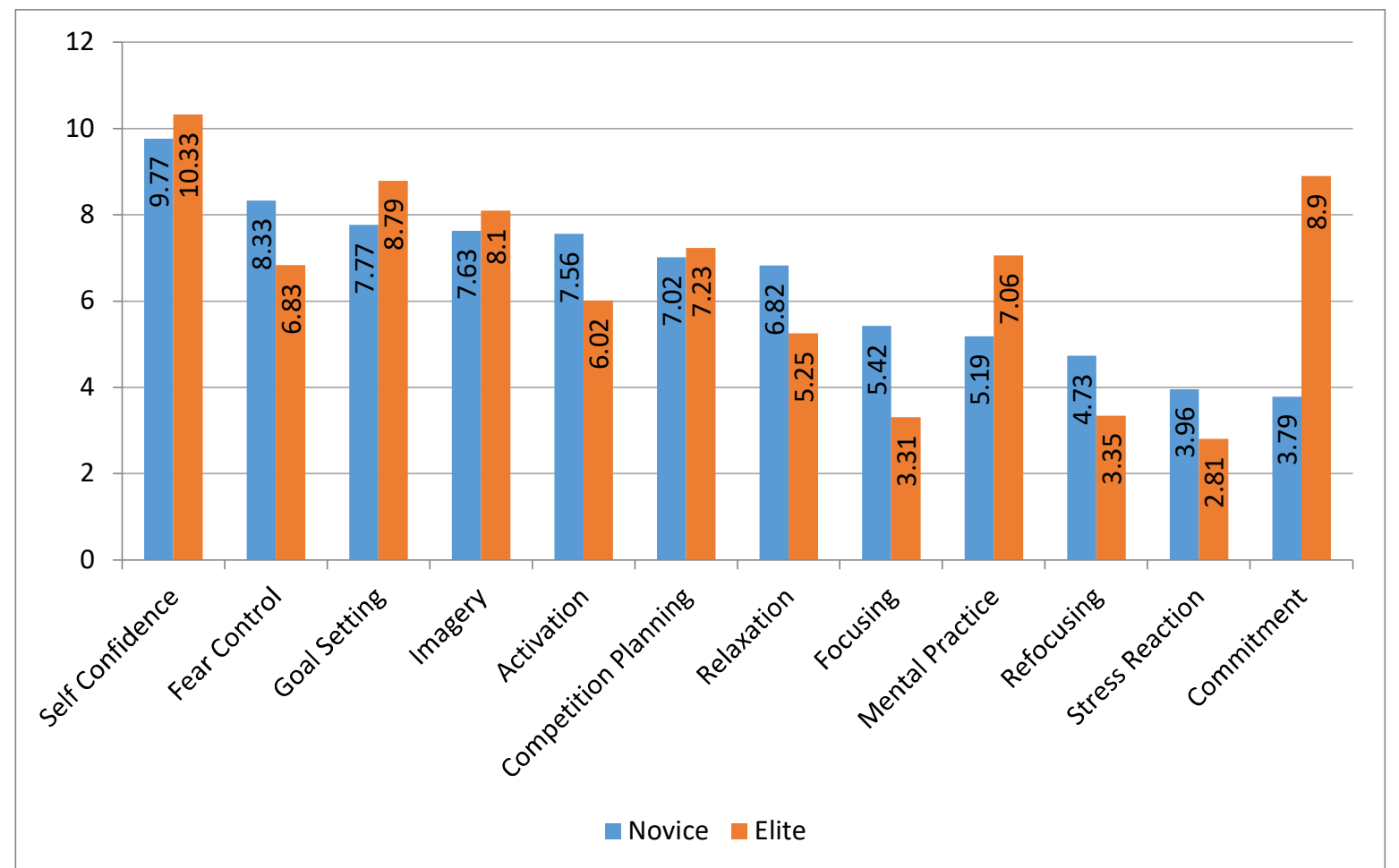

Figure 1. The results of Friedman's test for ranking the sub-scales of Ottawa's mental skills in elite and beginner groups.

\section{Discussion and Conclusion}

The aim of this study was to compare the psychological skills of elite and beginner Darts throwers and determine the ranking of their subscales of psychological skills. The results of this study showed that elite and beginner Darts throwers vary when applying foundation skills, as well as the subscale of commitment, which is consistent with the theoretical bases associated with the psychological skills of elite and beginner athletes. In this regard, it was stated that foundation skills are one of the best scales for elite and beginner athletes (Krane et al., 2014). Also, the higher level of psychological skills will not evolve in athletes without prior development of foundation skills (Durand-Bush et al., 2001). It was also stated that basic skills were among the skills that elite taekwondo athletes had higher scores than non-elites (Sotoodeh et al., 2012). therefore, foundation skills are one of the best scales for distinguishing between elite and beginner athletes (Krane et al., 2014). 
The results of this study showed that the sub-scales of self-confidence, commitment and goal-setting were ranked first to third, respectively, by elite Darts throwers, these results were in accordance with the norm presented by (Zeidabadi et al., 2014) who found that these sub-scales are ranked as good in athletes. However, in the case of beginner Darts throwers ranked as very low in commitment skill, low in goal-setting, and medium in self-confident. This result is inline with (Muasya et al., 2018) that found hockey and volleyball player had the higher score in self-confidence followed by goal setting and commitment which recorded the lowest score. These results are consistent with the results of previous studies which stated that the high levels of commitment, goal-setting, and self-confidence, are among the most prevalent of psychological characteristics of elite athletes, therefore are important elements in their success (Andrew, Potgieter, \& Grobbelaar, 2007; Eklund, 1996; Krane et al., 2014; Mahoney, Gabriel, \& Perkins, 1987; Orlick \& Partington, 1988; Sotoodeh et al., 2012). Also, by examining the psychological skills of elite field hockey players, it was found that the sub-scales of goal-setting, self-confidence, and commitment had the highest ranks among psychological skills (Eloff et al., 2011). Also, it was stated that commitment, goal-setting, and selfconfidence are among the most important components of success and are used at higher levels of performance than other mental skills (Eklund, 1996). In general agreement, researchers (Sharififar \& Vaez Mousavi, 2007; Vaez Mousavi $\&$ Mosayebi, 2007) stated that, elite athletes had higher scores in foundation skills than psychosomatic and cognitive skills (Adams, 1991; Durand-Bush et al., 2001; Khanjari, Arab Ameri, Garooei, Motashareei, \& Hemayattalab, 2013) which is consistent with the results of this study. It was demonstrated that the superiority of elite athletes compared to non-elite athletes are in goalsetting skill which also have particular direction in their (realistic) goals (Burton, 1989). and shortterm goals in conjunction with long-term goals, would be more effective alone (Locke \& Latham, 1985); therefore, it seems that in the present study, elite Darts throwers have short-term goals along with realistic long-term goals. Thus, the results of the present study are consistent with the results of (Andrew et al., 2007; Mirzaee et al., 2007; Muasya et al., 2018; Zareian, 2005) which showed that elite athletes, due to regular exercise, experience and frequent matches have high levels of mental skills when compared to their lower-level counterparts. However, amongst the elite throwers included in the present study concentration, relaxation, activation and stress-reaction is at low to medium levels, which is inconsistent with the results of the previously mentioned research. It seems that this discrepancy is related to the difference in sport disciplines, such as being individual or team, the level of skill, or age of the performers.

The results of this study revealed no difference between the psychosomatic and cognitive skills of the elite and beginner Darts throwers; however, elite Darts throwers were superior in the subscale of mental practice skills when compared to their beginner counterparts. Therefore, the results of this 
study is consistent with Stroub (Straub, 1989) who found that elite Darts throwers are superior in using a variety of mental exercises compared to beginner Darts throwers. The results of Stroub (1989) also indicate the difference between the elite and beginner Darts throwers in the effective use of mental exercises; so that the effectiveness of a variety of mental exercises is identical for elite Darts throwers, but in the beginner Darts throwers, different types of mental exercises have different impact and efficiency (Straub, 1989). It seems that the use of more mental exercises among elite Darts throwers may be due to the limited focus of attention in the field of Darts throwing and higher needs for focus and attention in the sport. These results are consistant with (Muasya et al., 2018) who found that hockey and vollybal player had higher score in mental practice and lower score in focus of attention. On the other hand, the sub-scales of stress response, concentration and Refocusing of the elite Darts throwers are at the medium to low levels. However, the results of (Krane et al., 2014; Mahoney et al., 1987; Orlick \& Partington, 1988; Shahbazi, Tahmasebi Boroujeni, \& Motasharee, 2014) showed that high concentration and Refocusing are among the characteristics of champion and elite athletes, which is inconsistent with the results of the current research. It was argued that elite athletes can better concentrate in closed skills, and are more likely to recover after failure and re-focus for the next action (Grandjean, Taylor, \& Weiner, 2002), which is not in line with the results of the present study. It appears that the low level of concentration and stress reaction in elite Darts throwers is due to the effect of external and internal stimuli such as the venue of the tournament, the behavior of referees and opponents, the expectation of parents and peers, fear of failure, pride, thoughts and feelings.

Additionally, it was stated that skill development and preparedness are two common goals for athletes. Thus, athletes whose purpose is to learn new skills (skill development) act differently in applying psychological skills techniques to athletes who try to prepare themselves psychologically a few minutes before the contest (ready to run) (Russell, Robb, \& Cox, 1998); therefore it seems that elite Darts players, due to the conditions of the competition, could not use their cognitive and psychosomatic skills effectively, which indicates they need more attention and practice of these skills. While beginner athletes, whose goal was probably learning the skills, have been able to properly use their mental skills in simulated competition conditions. Therefore, it seems necessary for coaches and sport psychologists to make further efforts to perfect these skills amongst Iranian elite Darts throwers.

Studies on the psychological characteristics of athletes in different sports show that, depending on the nature and type of sports, different mental skills are effective to their optimal performance. Furthermore, athletes with various levels of skill and competitive experience have different psychological profiles, consequently, psychological profiles of elite athletes can often be distinguished from athletes who have lower skill levels. The results of this study have highlighted 
the psychological profile, weaknesses and strengths of the psychological skills employed by elite and beginner Iranian Darts throwers.

Finally, the findings of this study are based on available sample of Dart throwers. therefore we have limitation to make strong inferences about the whole population of dart throwers, which is inevitable in such studies with convenience method of sampling like (Magnúsdóttir, 2017; Pickering, Hammermeister, Ohlson, Holliday, \& Ulmer, 2010). Clearly the need exists for more comprehensive study with larger sample size. However, these results give insights to this point that how mental skills differentiate performance of elite and beginner players which are important for best athletic performance in different sport disciplines specially athletes of Dart throwing.

\section{References}

1. Adams, L. B. (1991). A comparative analysis of cognitive differences among female elite and nonelite high school field hockey players and high school physical education class nonathletes. State University of New York.

2. Afsanepurak, S. A., Bahram, A., \& Dana Amir, A. J. (2012). The Effect of Self-talk and Mental Imagery on Self-efficacy in Throwing Darts in Adolescents. International Research Journal of Applied and Basic Sciences, 3(3), 594-600.

3. Aghdasi, M., Torabi, F., \& Touba, N. (2013). The comparison of the effects of instructional self-talk on girl's learning and performance of dart throwing in late childhood with adolescence. Motor Behavior (Research on Sport Science), 5(12), 83-96 In Persian.

4. Andrew, M., Potgieter, J. C., \& Grobbelaar, H. W. (2007). Sport psychological skill levels and related psychosocial factors that distinguish between rugby union players of different participation levels. South African Journal for Research in Sport, Physical Education and Recreation, 29(1), 1-14.

5. Burton, D. (1989). Winning isn't everything: Examining the impact of performance goals on collegiate swimmers' cognitions and performance. The Sport Psychologist, 3(2), 105-132.
6. Cumming, J., Nordin, S. M., Horton, R., \& Reynolds, S. (2006). Examining the direction of imagery and self-talk on dart-throwing performance and self efficacy. The Sport Psychologist, 20(3), 257-274.

7. Dahm, S. F., \& Rieger, M. (2019). Is imagery better than reality? Performance in imagined dart throwing. Human Movement Science, 66, 38-52. https://doi.org/https://doi.org/10.1016/j.humov.201 9.03.005

8. Durand-Bush, N., Salmela, J. H., \& Green-Demers, I. (2001). The Ottawa mental skills assessment tool (OMSAT-3*). The Sport Psychologist, 15(1), 1-19.

9. Eklund, R. C. (1996). Preparing to compete: A season-long investigation with collegiate wrestlers. The Sport Psychologist, 10(2), 111-131.

10. Eloff, M., Monyeki, M. A., \& Grobbelaar, H. W. (2011). A survey of mental skills training among South African field hockey players at tertiary institutions:: sport psychology. African Journal for Physical Health Education, Recreation and Dance, 17(1), 37-50.

11. Esfahani, N., \& GHezelseflo, H. (2013). The comparison of psychological skills of Elite and nonElite Karate ka and its relation with athletes' performance. Psychological Studies, 9(1), 109-120. In Persian.

12. Grandjean, B. D., Taylor, P. A., \& Weiner, J. (2002). Confidence, Concentration, and Competitive Performance of Elite Athletes: A Natural Experiment in Olympic Gymnastics. Journal of Sport \& Exercise Psychology, 24(3).

13. Heydari, A., Soltani, H., \& Mohammadi-Nezhad, M. (2018). The effect of Psychological skills training (goal setting, positive selftalk and Imagery) on self-confidence of adolescent volleyball players. Pedagogics, Psychology, Medical-Biological Problems of Physical Training and Sport, 22(4), 189-194. https://doi.org/10.15561/18189172.2018.0404

14. Khanjari, Y., Arab Ameri, E., Garooei, R., Motashareei, E., \& Hemayattalab, R. (2013). The Effect of a Course of Psychological Skills Training (PST) Program on Selected Mental Skills and the Performance of Teenager Female Taekwondo Athletes of Iranian National Team. JRSM, 3(5), 2534 In Persian.

15. Krane, V., Williams, J. M., \& Williams, J. M. (2014). Applied sport psychology: Personal growth to peak performance. Mcgraw-hill EducationEurope.

16. Locke, E. A., \& Latham, G. P. (1985). The application of goal setting to sports. Journal of Sport and Exercise Psychology, 7(3), 205-222.

17. Low, G. R., \& Nelson, D. B. (1994). Good Darts: Improving Your Game with Psychological and Selfmastery Skills. Good Darts Press. Retrieved from https://books.google.com/books?id=DtQ9HQAAC AAJ 
18. Magnúsdóttir, Í. M. (2017). Athletes mental skills and stress factors: in the preparation of competing at the Olympic Games. Reykjavík University,.

19. Mahoney, M. J., Gabriel, T. J., \& Perkins, T. S. (1987). Psychological skills and exceptional athletic performance. The Sport Psychologist, 1(3), 181199.

20. Mirzaee, B., Rahmani-nia, F., \& Bordar, F. (2007). Compare the profile of mental skills wrestlers' junior and senior national teams in freestyle and Greco-Roman. Harakat Journal, 34, 62-89 In Persian.

21. Muasya, V., Oloo, J. A., Mustafa, P. H., Kamau, G. G., Munene, D. M., Walingo, M. J., ... Rotich, A. K. (2018). Analysis of the Mental Skills Status of Volleyball and Field Hockey Players in National League Clubs in Kenya. Kenyatta University. Retrieved from http://irlibrary.ku.ac.ke/handle/123456789/19199

22. Orlick, T., \& Partington, J. (1988). Mental links to excellence. The Sport Psychologist, 2(2), 105-130.

23. Pashabadi, A., Shahbazi, M., Hoseini, S. M., Mokaberian, M., Kashanai, V., \& Heidari, A. (2011). The Comparison of mental skills in elite and sub-elite male and female volleyball players. Procedia-Social and Behavioral Sciences, 30, 1538-1540.

24. Pickering, M. A., Hammermeister, J., Ohlson, C., Holliday, B., \& Ulmer, G. (2010). An exploratory investigation of relationships among mental skills and resilience in warrior transition unit cadre members. Military Medicine, 175(4), 213-219.

25. Russell, W. D., Robb, M., \& Cox, R. H. (1998). Sex, sport, situation, and competitive state anxiety. Perceptual and Motor Skills, 86(3), 816-818.

26. Shahbazi, M., Tahmasebi Boroujeni, S., \& Motasharee, E. (2014). Determination of factorial validity and reliability of person version of test of performance strategies-2 (TOPS-2). Motor Behavior, 6(17), 15-42 In Persian.

27. Sharififar, F., \& Vaez Mousavi, M. K. (2007). Psychology mental preparation of athletes admitted to the National Olympic Academy. National Olympic Committee of the Islamic Republic of Iran, 96-100 In Persian.

28. Sotoodeh, M. S., Talebi, R., Hemayattalab, R., \& Arabameri, E. (2012). Comparison of selected mental skills between elite and non-elite male and female Taekwondo athletes. World Journal of Sport Sciences, 6(1), 32-38.

29. Straub, W. F. (1989). The effect of three different methods of mental training on dart throwing performance. The Sport Psychologist, 3(2), 133141.

30. Taylor, J. E., \& Wilson, G. E. (2005). Applying sport psychology: Four perspectives. Human Kinetics.

31. Vaez Mousavi, M. K., \& Mosayebi, F. (2007). Sports Psychology (1st Ed.). Samt Publication.

32. Vazini Taher, A., \& Shahbazi, M. (2013). Functional Capacities and Mental Skills Necessary for Expertise in Soccer. Iranian Journal of Health and Physical Activity, 4(1).

https://doi.org/10.22067/ijhpa.v4i1.21172

33. Weber, E., \& Doppelmayr, M. (2016). Kinesthetic motor imagery training modulates frontal midline theta during imagination of a dart throw. International Journal of Psychophysiology, 110, 137-145.

https://doi.org/https://doi.org/10.1016/j.ijpsycho.20 16.11 .002

34. Weinberg, S. R., \& Gould, D. (2007). Foundation of SportandExercisePsychology. Champaign, IL: Human Kinetics Publishers. S40.

35. Zareian, M. (2005). Compare the profiles of elite judo men's mental skills in three age categories (adult, youth, and teenager). master thesis. Islamic Azad University of Karaj.

36. Zeidabadi, R., Rezaie, F., \& Motashareie, E. (2014). Psychometric properties and normalization of persian version of ottawa mental skills assessment tools (OMSAT-3). Sport Psychology Review, 3(7), 63-82.

37. Zhang, C.-Q., Si, G., Duan, Y., Lyu, Y., Keatley, D. A., \& Chan, D. K. C. (2016). The effects of mindfulness training on beginners' skill acquisition in dart throwing: A randomized controlled trial. Psychology of Sport and Exercise, 22, 279-285. https://doi.org/https://doi.org/10.1016/j.psychsport. 2015.09.005. 